\title{
MANAGEMENT AND SURGICAL OUTCOMES OF ADULT SPINAL INTRADURAL LESIONS: A RETROSPECTIVE STUDY
}

\section{(1) Murad ASILTÜRK' ${ }^{1}$, (1) Anas ABDALLAH², (1) Özden Erhan SOFUOĞLU1', (1) Rashid AVYASOV³, (1) Meliha Gündağ PAPAKER²}

\author{
${ }^{1}$ University of Health Sciences Turkey, Bakırköy Training and Research Hospital, Clinic of Neurology, Neurosurgery and Psychiatry, Istanbul, \\ Turkey \\ ${ }^{2}$ Bezmialem Vakif University, Faculty of Medicine, Department of Neurosurgery, Istanbul, Turkey \\ ${ }^{3}$ Special Aile Hospital, Clinic of Neurosurgery, Istanbul, Turkey
}

\begin{abstract}
Objective: Spinal intradural lesions (IDLS) range from benign lesions to lethal malignant tumours. Approaches to treat the spinal lesions depend on their nature. This study aims to summarise our approach and strategies in treating IDLs by evaluating the surgical outcomes of 53 consecutively operated patients.

Materials and Methods: We retrospectively reviewed the medical records of 53 patients with spinal IDLs who underwent surgery at our institute spanning 6 years, from January 1992 to December 1997. The long-term surgical outcomes were evaluated. Based on the relevant literature, our surgical approaches and strategies were discussed.

Results: Overall, 53 cases were enrolled, 25 women and 28 men. The mean age was $52.2 \pm 18.4$ years. The most common symptom was radicular pain (88.7\%). Histopathologic diagnoses were meningioma ( $n=16)$, schwannoma $(n=11)$, ependymoma $(n=9)$, astrocytoma $(n=6)$, lipoma $(n=3)$ and other pathologies in eight cases. Gross-total (GTR), near-total (NTR) and subtotal (STR) resections were achieved in 34, six and 13 patients, respectively. Although 45 (84.9\%) patients underwent total laminectomy, only one patient underwent fixation with posterior instrumentation after GTR 13 years later, when he presented with the progression of subtotally resected schwannoma. Intramedullary location was an independent factor to perform STR instead of GTR or NTR $(p=0.032)$.

Conclusion: The treatment approach for IDLs depends on several factors, such as the patient's age, estimated survival, the nature of the lesion and the presenting symptoms. Based on the need for postoperative posterior fixation, we did not observed a statistical difference supporting the superiority of hemilaminectomy over total laminectomy. Nevertheless, further large, prospective studies are needed to support our findings. Keywords: Spinal tumour, management, surgical approach, histopathological diagnosis, intradural lesion
\end{abstract}

\section{INTRODUCTION}

The spinal anatomy is a complex architecture consisting of 34 variously shaped and morphologically distinct vertebrae. This anatomy is frequently the restricting factor in performing surgical excision of neoplastic spinal lesions. Several factors have to be considered before treatment of the spinal tumours, such as the nature of the tumour, the estimated survival time, the morbidity of the lesion, the tumour's malignant potential, the location of the lesion, the comorbidities, the patient's age, symptoms of clinical presentation and overall prognosis. All these factors must be compared to the morbidity and potential mortality of radical resection of a tumour located near the neural tissues of medulla spinalis and nerve roots. Spinal tumours produce non-specific symptoms and may require to generate considerable suspicion to be investigated ${ }^{(1-3)}$.
After the description of spinal tumour resection through laminectomy in 1887 by Sir Victor Horsley, the management of the spinal tumours have improved ${ }^{(4)}$. Notably, most primary spinal cord tumours are histopathologically similar to primary intracranial tumours, although spinal cord tumours are 10 times less commonly observed ${ }^{(2)}$. Because of the non-specific clinical presentation, patients may present with serious radicular or local pain and motor dysfunction ${ }^{(5-7)}$. Therefore, most patients are wrongly diagnosed with degenerative spinal disease, cervical spondylopathy or intervertebral disc herniation ${ }^{(3,6,7)}$.

Presently, magnetic resonance imaging (MRI) is considered the gold standard for scanning all neoplastic lesions. MRI delineates the soft-tissue components and enables accurate diagnoses. Preliminary diagnosis obtained using MRI can help to plan the surgical intervention and reduce complications that may occur from surgery. Therefore, preoperative MRIs are essential before the surgical treatment of spinal tumours ${ }^{(1,6)}$.

Address for Correspondence: Anas Abdallah, Bezmialem Vakif University, Faculty of Medicine, Department of Neurosurgery, İstanbul, Turkey E-mail: abdallahanas@hotmail.com Received: 27.01.2020 Accepted: 29.04.2020

ORCID ID: orcid.org/0000-0003-3600-089X 
Notably, the metastatic and high-grade malignant spinal lesions are associated with high morbidity and mortality. The consensus among spinal surgeons regarding the primary treatment of choice for spinal lesions is to perform gross-total resection (GTR) with preservation of neurological functions. GTR of spinal lesions provides excellent clinical outcomes in patients with moderate clinical findings( ${ }^{(6,7)}$. Nevertheless, the surgical approach depends on the location, the spinal surgeon's familiarity, size and extension of the lesion. Furthermore, the use of intraoperative neurophysiological monitoring (IONM) has been noted to improve the extent of tumour resection with increased safety, particularly for intradural spinal lesions (IDLs) ${ }^{(1,6,7)}$. Nonetheless, the prognosis for patients with spinal lesions, especially IDLs, depends on the patient's age at diagnosis, neurological status at presentation, the extent of the disease and the histopathologic diagnosis, which is the major factor in deciding the treatment approach suitability ${ }^{(1,7)}$. This study aimed to summarise the treatment approaches for spinal IDLs by evaluating the long-term surgical outcomes of 53 consecutively operated patients with spinal IDL. Furthermore, the applied surgical approaches and long-term outcomes were discussed based on the relevant literature.

\section{MATERIALS AND METHODS}

\section{Patient Data, Study Design and Study Criteria}

This retrospective study was approved by the medical ethics committee of our hospital (Bakırköy Training and Research Hospital) in December 2015, bearing decision number 2015/508. All patients consented to surgical procedures. Written informed consent was obtained from all patients for publication of their cases and accompanying images.

We retrospectively reviewed the medical records of 110 patients with spinal tumours who underwent surgery at our institute spanning 6 years, from January 1992 to December 1997. Only patients who underwent spinal operation for the spinal IDLs detected on MRI were included ( $n=53)$.

The inclusion criteria were as follows: 1) patients who underwent surgical resection [GTR, near-total resection (NTR) or subtotal resection (STR)] for spinal IDLs (patients who underwent diagnostic biopsy were excluded), 2) diagnosis based on MRI findings, 3) patients with proven pathologic diagnosis of the material obtained from spinal surgery and 4) patients older than 15 years.

Exclusion criteria were as follows: 1) patients who underwent resection for recurrent lesions, 2) a history of multiple malignant lesions in all organs of the body (patients with multiple metastases), 3) patients who underwent diagnostic biopsy, 4) presence of contraindication for performing MRI and 5) patients who underwent resection of the spinal lesion determined using computerised tomography and not preoperative MRI.

GTR was defined as resection of the whole tumour mass under microscope. NTR was defined as removal of more than $95 \%$ of the tumour mass leaving the tumour pieces attached to the critical neural structure. If the resected tissue was less than $95 \%$ and more than $75 \%$ of the tumour mass, the surgical resection was defined as STR. These resections were performed under a microscope and confirmed using early postoperative MRI (in the first $24 \mathrm{~h})^{(8)}$.

The long-term surgical outcomes were evaluated. Our surgical approaches and strategies were discussed based on the relevant literature.

\section{Surgical Procedure}

Under general anaesthesia and using IONM, patients were positioned prone by using a supporting-roll on each side. A paramedian vertical midline incision was performed. After dissecting the paraspinal muscles, laminectomy or hemilaminectomy was performed. Bilateral laminotomies were performed using high-speed drills or Kerrison rongeurs. The ligamentum flavum and adipose tissue were then removed. The laminectomy or laminotomy was performed up to the tumour spanned levels. The operative microscope was brought into the operation field. The thecal sac was opened in the midline and tacked up bilaterally using strong sutures. After the dura was opened, a dorsal midline myelotomy was performed on any intramedullary lesions to reach the intramedullary region. After exposure, all nerve roots, spinal cord or terminal filum, arachnoid bands and neural tissues were distinguished from the tumoural tissue using the microscope and probe of IONM. After haemostasis using physiologic saline water and tight closure of dura by using 5.0 absorbable sutures, a duraplasty was performed using Fibrin Sealant Products (TISSEEL ${ }^{\circledR}$; Baxter Company; USA). The operative field was kept clean, and the CSF circulation between the neural elements was preserved. All layers were closed appropriately with their anatomy ${ }^{(1,6,7,9)}$.

\section{Statistical Analysis}

All data were expressed as the median or mean \pm standard deviation with the range depicted in parentheses. Univariate analyses were conducted to examine the association between radiological and histopathological features. Intergroup differences between were assessed using Fisher's exact test and student's t-test with the SPSS 21.0 statistical package. Significance was determined using a $p$ value of $<0.05$, and trend-level effects were defined as $p=0.05-0.10$. All $p$ values were presented with an odds ratio (OR). OR were presented with the $95 \%$ confidential interval. When the OR could not be calculated, the risk ratio was calculated. All tests were twotailed.

\section{RESULTS}

\section{Patients' Characteristics and Surgical Treatment}

Overall, 110 spinal tumours were operated at our institute during the period of the study. Of these, 57 tumours were excluded because they did not meet our study criteria. The final study sample comprised 53 patients, 25 women (47.2\%) and 28 men (52.8\%). The mean age was $52.2 \pm 18.4$ years $(21-73$ 
years). The most common symptom was radicular pain (upper or lower extremities pain) (88.7\%) $(n=47)$, followed by motor deficit (84.9\%) ( $n=45)$, loss of sensation (69.8\%) ( $n=37)$, as well as lower motor neuron findings including change in reflexes (50.9\%) $(n=27)$ and sphincter dysfunctions, such as urinary or faecal incontinence or retention (37.7\%) $(n=20)$. The mean duration of preoperative symptoms was $4.2 \pm 5.9$ years ( 0.33 15 years). Metastases (neuro-axis dissemination seeding of glioblastoma and germinoma) and high-grade glial tumours had a short preoperative course (short duration of symptoms) with an average of $8.9 \pm 3.4$ months (4-16 months). On the other hand, meningiomas, schwannomas and lipomas had a relatively long preoperative course with an average of $4.6 \pm 6.9$ years $(0.5$ 15 years) (Table 1 ).

Table 1. Baseline demographic and clinical characteristics of investigated 53 patients with spinal intradural tumours

\begin{tabular}{|c|c|}
\hline & $\begin{array}{l}\text { Number of the patients (\%) } \\
n=53\end{array}$ \\
\hline \multirow{2}{*}{ Gender } & Female: 25 (47.2\%) \\
\hline & Male: 28 (52.8\%) \\
\hline Age (years) & $52.2 \pm 18.4(21-73)$ \\
\hline \multirow{2}{*}{ Location according medullary } & Extramedullary: 38 (71.7\%) \\
\hline & Intramedullary: 15 (28.3\%) \\
\hline \multirow{3}{*}{ Surgical resection } & $\begin{array}{l}\text { Gross total resection: } 34 \\
(64.2 \%)\end{array}$ \\
\hline & Near-total resection: 6 (11.3\%) \\
\hline & Subtotal resection: 13 (24.5\%) \\
\hline \multirow{5}{*}{ Clinical presentation } & Radicular pain: 47 (88.7\%) \\
\hline & Motor deficit: 45 (84.9\%) \\
\hline & Loss of sensation: 37 (69.8\%) \\
\hline & $\begin{array}{l}\text { Lower motor neuron reflex: } 27 \\
(50.9 \%)\end{array}$ \\
\hline & $\begin{array}{l}\text { Sphincter dysfunction: } 20 \\
(37.7 \%)\end{array}$ \\
\hline \multirow{12}{*}{$\begin{array}{l}\text { Proven histopathlogical } \\
\text { diagnosis }\end{array}$} & Meningioma: 16 (30.1\%) \\
\hline & Schwannoma: 11 (20.8\%) \\
\hline & Ependymoma: 9 (17.0\%) \\
\hline & Astrocytoma: 6 (11.3\%) \\
\hline & Lipoma: 3 (5.6\%) \\
\hline & Epidermoid Cyst: 2 (3.8\%) \\
\hline & Hemangioblastoma: 1 (1.9\%) \\
\hline & Ganglioglioma: 1 (1.9\%) \\
\hline & Paraganglioglioma: 1 (1.9\%) \\
\hline & Cavernous angioma: 1 (1.9\%) \\
\hline & $\begin{array}{l}\text { Germinoma seeding } \\
\text { metastasis: } 1(1.9 \%)\end{array}$ \\
\hline & $\begin{array}{l}\text { Glioblastoma seeding } \\
\text { metastasis: } 1 \text { (1.9\%) }\end{array}$ \\
\hline Preoperative course (years) & $4.2 \pm 5.9(0.33-15)$ \\
\hline
\end{tabular}

\section{Histopathological Diagnosis and Locations of Tumours}

Histopathological diagnosis was meningioma in 16 (Figure 1), schwannoma in 11 (Figure 2), ependymoma in nine (Figure 3), astrocytoma in six, lipoma in three and others in eight cases (epidermoid cyst in two, haemangioblastoma in one, ganglioglioma in one, paraganglioglioma in one, cavernous angioma in one, cervical seeding metastasis of suprasellar germinoma in one and cervical seeding metastasis of glioblastoma multiforme in one).

Overall, 53 cases were intradural lesions (38 extramedullary and 15 intramedullary). Locations of meningioma were the thoracic and cervical spines in 14 and two cases, respectively. The thoracic spine was the most affected with meningioma $[p<0.001 ; O R=0.1$ (0.01-0.3)] (Table 2). The accuracy of MRI (i.e. compatibility of MRI with histopathological diagnosis) is presented in Table 3. Hypo-, iso- and hyperintensity on T1-weighted imaging (T1WI), T2-weighted imaging (T2WI) and contrast-enhanced T1WI (C+T1WI) sequences of histopathologically confirmed and the four most misdiagnosed spinal pathologies are provided in Table 4. Even though MRI cannot diagnose all cases of these tumours, it had a high accuracy rate of up to $71.7 \%$.

\section{Management, Approaches and Surgical Outcomes (Table 5)}

Notably, 32 of the 38 extramedullary lesions underwent GTR and NTR (28 and four, respectively) compared with eight of 15 intramedullary lesions that underwent GTR and NTR (six and

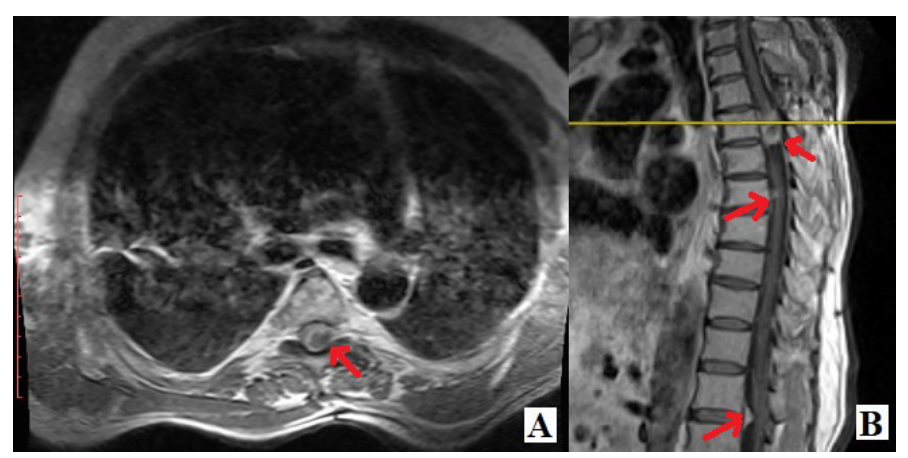

Figure 1. Lumbar and thoracic MRIs of a 66-year-old male patient who experienced back pain for 2 years. The patient has a history of T4 laminectomy 20 years ago and biopsy for suspected prostate carcinoma but the biopsy revealed no carcinoma cells. No history of neurofibromatosis type 2 was known. A) Axial C+T1WI sequence of thoracic MRI revealed heterogeneously enhanced intradural extramedullary hypointense lesion at the T5 level that was compressing the left side of spinal cord. B) Sagittal C+T1WI sequence of thoracic MRI revealed multiple involvements of intradural extramedullary lesion on the T5, and lesion at the T7 and T12-L1 levels that was suspected to be metastasis. He underwent NTR of an intradural lesion at the T5 level with a laminectomy. The lesion was confirmed to be a meningothelial meningioma WHO grade I. After physical therapy rehabilitation, the patient was doing well without recurrence. Red arrows indicate multiple lesions

MRI: Magnetic resonance imaging, NTR: Near-total resection, WHO: World Health Organisation 
Table 2. Locations of investigated 53 patients with intradural tumours

\begin{tabular}{|c|c|c|c|}
\hline Histopathological Diagnosis & Cervical & Thoracic & Lumbar \\
\hline Meningioma $(n=16)$ & 2 & 14 & - \\
\hline Schwannoma $(n=11)$ & 4 & 3 & 4 \\
\hline Ependymoma $(n=9)$ & 4 & 1 & 4 \\
\hline Astrocytoma $(n=6)$ & $5^{*}$ & 1 & - \\
\hline Lipoma $(n=3)$ & - & 2 & 1 \\
\hline Epidermoid Cyst ( $n=2)$ & - & 1 & 1 \\
\hline Hemangioblastoma $(n=1)$ & 1 & - & - \\
\hline Ganglioglioma (n=1) & 1 & - & - \\
\hline Paraganglioglioma $(n=1)$ & - & - & 1 \\
\hline Cavernous angioma $(n=1)$ & - & 1 & - \\
\hline $\begin{array}{l}\text { Germinoma seeding metastasis } \\
(n=1)\end{array}$ & 1 & - & - \\
\hline $\begin{array}{l}\text { Glioblastoma seeding } \\
\text { metastasis }(n=1)\end{array}$ & 1 & - & \\
\hline Total & 19 & 23 & 11 \\
\hline
\end{tabular}

$\mathrm{n}$ : Number of the patients

* 3 astrocytomas were span from the cervical region to thoracic but we accepted it as cervical because they largely occupied cervical more than the thoracic spine

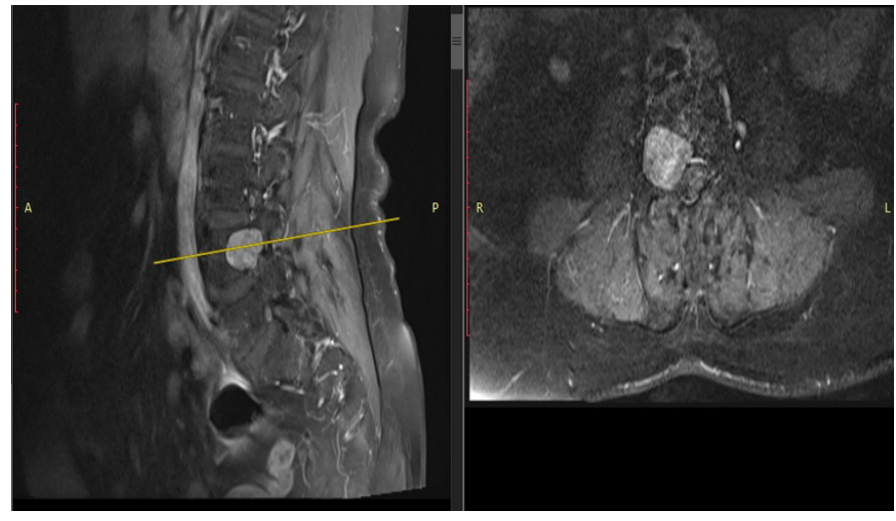

Figure 2. A 70-year-old female patient who experienced low back and right leg pain for 5 months. C+T1Wls revealed a well-circumscribed lesion that eroded the right pedicle of the $L 4$ vertebra and measured $27 \times 28 \times 16 \mathrm{~mm}$, narrowed right L4 foramen and heterogeneous enhancement after contrast. She underwent an operation and neurosurgeons identified the lesion to be intradural extramedullary intraoperatively. GTR was performed. The lesion was confirmed to be a schwannoma. The patient's pain was relieved, and she was intact neurologically on her fifth-year postoperative control visit. Left side: sagittal C+T1WI; right side: axial C+T1WI GTR: Gross-total resection, MRI: Magnetic resonance imaging, WHO: World Health Organisation

Table 3. Radiologic and histopathologic correlation in our intradural lesions

\begin{tabular}{lllllll} 
MRI diagnosis & $\mathrm{n}$ & Confirmed & Misdiagnosed & $\%$ & $p$ & OR \\
\hline Meningioma & 17 & 14 & Sch (2); Ep & 82.4 & $<0.001$ & $0.02(0.003-0.15)$ \\
\hline Schwannoma & 10 & 8 & Mening; Ep & 80.0 & $<0.001$ & $0.05(0.01-0.22)$ \\
Ependymoma & 10 & 5 & $\begin{array}{l}\text { Sch; Seeding GBM; } \\
\text { Paragang; Astro; CA }\end{array}$ & 41.7 & 0.02 & $0.15(0.03-0.71)$ \\
\hline Astrocytoma & 10 & 5 & $\begin{array}{l}\text { Ep (2); Mening; Seeding } \\
\text { Germ; Ganglioglioma }\end{array}$ & 50.0 & 0.58 & $0.3(0.003-3.1)$ \\
\hline Lipoma & 3 & 3 & - & 100 & $<0.001$ & - \\
\hline Epidermoid cyst & 2 & 2 & - & 100 & 0.0014 & - \\
\hline Hemangioblastoma & 1 & 1 & - & 100 & 0.067 & - \\
\hline Total & 53 & 38 & $\mathrm{n}=15$ & 71.7 & - & -
\end{tabular}

CV: Cavernous angioma, p: probability, OR: Odds ratio, n: number of patients, \%: The accuracy percentage of MRI, Mening: Meningioma, Ep: Ependymoma, Sch: Schwannoma, Paragang: Paraganglioma, GBM: glioblastoma multiforme, Germ: Germinoma

Significant $p$ values shown as bold and italic

Table 4. Radiologic features of histopathologically confirmed and the most misdiagnosed four spinal intradural lesions

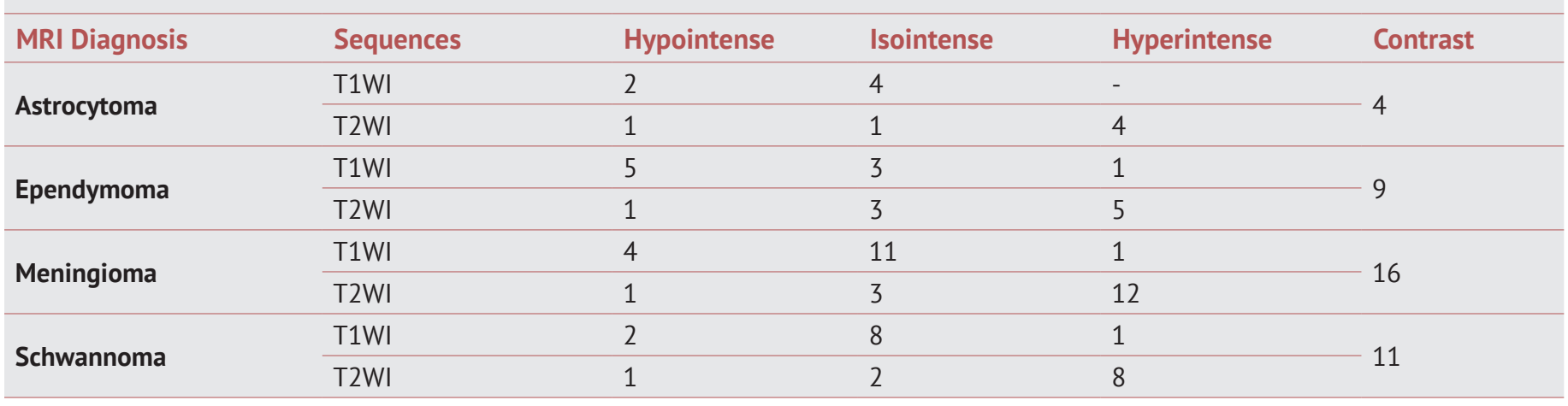


two, respectively). Intramedullary location was an independent factor in deciding to perform STR instead of GTR or NTR $[p=0.032 ; 0 R=0.2(0.06-0.82)]$.

Overall, 45 patients underwent laminectomy, whereas eight underwent hemilaminectomy (Table 5). A male patient presented with the same initial presentation symptoms of severe back pain and upper thoracic kyphosis after 13 years. The patient experienced progression of the thoracic (T3-5) schwannoma after he underwent STR with T3-5 laminectomy. In the second operation, he underwent GTR and posterior instrumentation. A female who patient underwent NTR with a T9-11 laminectomy for extramedullary thoracic epidermoid cyst at age 19 years experienced two recurrences after 2 and 5 years.

Furthermore, five patients $(9.4 \%)$ had worsened neurosurgical functions, nine (17.0\%) were unchanged and 39 (73.6\%) improved or fully recovered after surgical interventions. Notably, the location did not play any role in prognosis. Among the five patients who worsened after surgery, four had intramedullary and one had extramedullary lesions $(p=0.08$ and

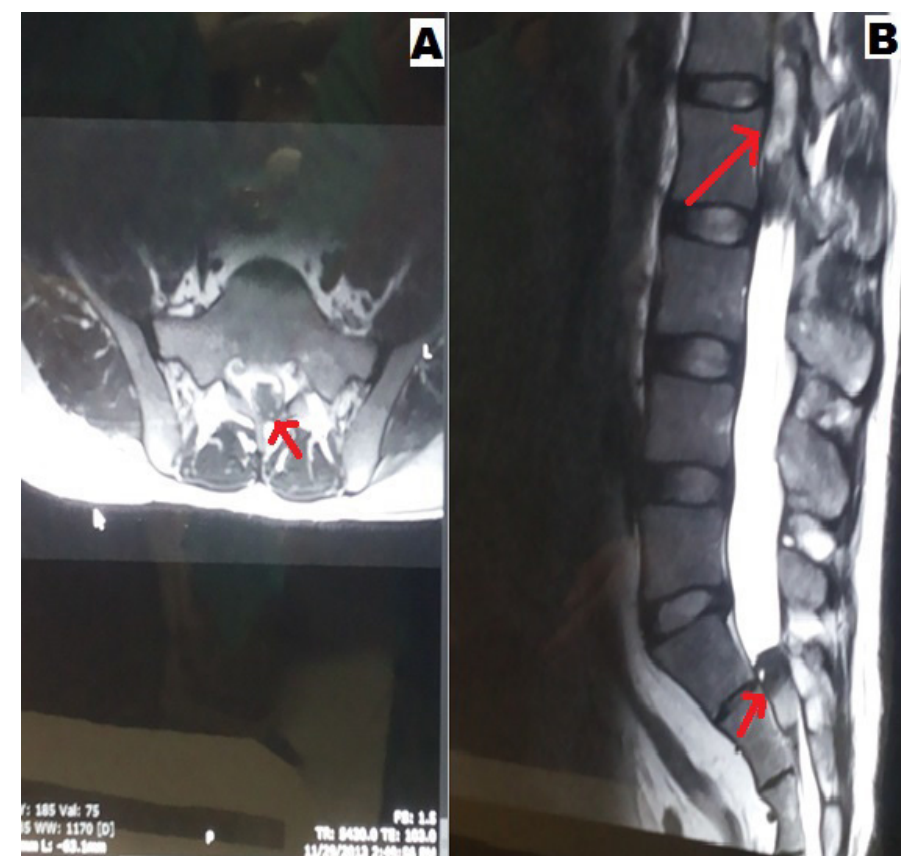

Figure 3. A 31-year-old male was referred to our emergency department with an unsteady gait, left leg numbness and weakness of seven weeks' duration. Retention of urine was developed over the past three days. Preoperative MRI demonstrated the presence of two well-circumscribed intradural extramedullary lumbar lesions at L1-2 and S2 levels. The lesions were hyperintense on T1WI and iso-hyperintense on T2WI. A) Axial T2WI at S1 level. B) Sagittal T2WI. GTR was performed for both lesions with two laminectomies. The lesions were confirmed to be WHO grade II classic ependymoma. The neurological examination did not change even after the patient underwent 30 sessions of physical therapy and rehabilitation. No recurrence or seeding was detected on his $272^{\text {th }}$ control visit. Red arrows indicate the lesions

MRI: Magnetic resonance imaging, GTR: Gross-total resection, WHO: World Health Organisation $p=0.12$, respectively). Among the 39 patients who improved or recovered, 30 had extramedullary and nine had intramedullary lesions ( $p=0.1$ and $p=0.2$, respectively). Moreover, two patients with seeding metastases, two patients with astrocytoma World Health Organisation (WHO) grade III and one patient with recurrent cervical classic ependymoma WHO grade II were provided radiotherapy after STR. Except for the two patients with seeding metastasis of glioblastoma and germinoma, no patient died of the disease. Two of the five patients who experienced CSF leakage needed surgeries to treat the leakage, whereas the remaining three patients were followed up with lumbar drainages. Two patients with astrocytoma presented with symptoms of the syrinx after 14 and 18 years and were treated with T-tube and syringopleural shunt, respectively.

Table 5. The modalities and approaches to our studied spinal patients according to their histopathological diagnosis

\begin{tabular}{|c|c|c|}
\hline Tumour & Applied modalities and approaches & $\mathbf{n}$ \\
\hline \multirow{5}{*}{$\begin{array}{l}\text { Meningioma } \\
\text { (16) }\end{array}$} & GTR with a laminectomy & 9 \\
\hline & GTR with a hemilaminectomy & 2 \\
\hline & NTR with a laminectomy & 2 \\
\hline & NTR with hemilaminectomy & 1 \\
\hline & STR with laminectomy & 2 \\
\hline \multirow{3}{*}{$\begin{array}{l}\text { Schwannoma } \\
\text { (11) }\end{array}$} & GTR with a laminectomy & 8 \\
\hline & GTR with a hemilaminectomy & 2 \\
\hline & STR with laminectomy (extramedullary) ${ }^{*}$ & 1 \\
\hline \multirow{4}{*}{$\begin{array}{l}\text { Ependymoma } \\
\text { (9) }\end{array}$} & GTR with a laminectomy & 3 \\
\hline & GTR with a hemilaminectomy & 2 \\
\hline & NTR with a laminectomy & 2 \\
\hline & STR with a laminectomy & 2 \\
\hline \multirow{3}{*}{$\begin{array}{l}\text { Astrocytoma } \\
\text { (6) }\end{array}$} & GTR with a laminectomy & 1 \\
\hline & NTR with a laminectomy & 2 \\
\hline & STR with a laminectomy & 3 \\
\hline Lipoma (3) & GTR with a laminectomy & 3 \\
\hline \multirow{2}{*}{$\begin{array}{l}\text { Epidermoid } \\
\text { (2) }\end{array}$} & GTR with a laminectomy & 1 \\
\hline & NTR with a laminectomy & 1 \\
\hline HA & GTR with a laminectomy & 1 \\
\hline Ganglioglioma & GTR with a laminectomy & 1 \\
\hline PG & GTR with a hemilaminectomy & 1 \\
\hline CA & GTR with a laminectomy & 1 \\
\hline GermSM & STR with a laminectomy & 1 \\
\hline GSM & STR with a laminectomy & 1 \\
\hline
\end{tabular}

HA: Hemangioblastoma, PG: Paraganglioglioma, CA: Cavernous angioma, GermSM, Germinoma seeding metastasis, GSM: Glioblastoma seeding metastasis, n: Number of the patients, GTR: Gross-total resection, NTR: Near-total resection, STR: Subtotal resection

${ }^{*}$ This patient presented with the same first presentation symptoms after 13 years, with severe back pain and upper thoracic kyphosis. The patient experienced the progression of thoracic (T3-5) schwannoma after underwent STR with a T3-5 laminectomy. In the second operation, he underwent GTR and PII 


\section{DISCUSSION}

The management of the spinal lesions should be based on the overall health of the patient and the degree of associated blood loss. Metastatic or systemic tumour involvement in a patient could be a contraindication for radical resection of the paraspinal tumour because it may render the patient paralysed. Nevertheless, the primary purpose of spinal tumour treatment is palliative. In addition, the other objectives of treatment are restoration or preservation of neurological function, pain control or relief and the maintenance of spinal column stability to improve the patient's life quality. Corticosteroids can reportedly decrease the spinal cord oedema and have an oncolytic effect on certain neoplastic lesions. Even though corticosteroid efficacy is still debatable, some authors have suggested regarding its analgesic effect and efficacy in preventing neurological deterioration, such as paralysis or paraplegia ${ }^{(4,10)}$.

A decompressive laminectomy is one of the most used approaches in the treatment of spinal tumours. Notably, a ventral burden of neoplastic lesion can destabilise the anterior column of the spine. Therefore, laminectomy without posterior instrumentation can worsen the clinical status and complaints of patients with spinal tumours ${ }^{(11,12)}$. Technical advances in spinal surgery that enable circumferential spinal cord decompression combined with posterior instrumentation have helped to design more aggressive and effective surgical interventions for patients with spinal IDLs $s^{(1,6)}$.

The most common intradural extramedullary (IDEM) lesions were meningioma, schwannoma, ependymoma, lipoma, epidermoid cysts and paraganglioma, whereas astrocytoma was the most common intradural intramedullary (IDIM) lesion observed in our series. All intradural lesions (IDEM + IDIM) can be treated with one of the following three approaches: 1) total laminectomy, 2) hemilaminectomy and 3) laminoplasty. Regarding the resection totality, IDEM lesions can be removed using one of the following five technique: GTR, NTR, STR, partial resection, or biopsy. Nevertheless, according to our criteria, we excluded the latter two techniques and only the former three were applied to our selected patients. All our study patients underwent laminectomy or hemilaminectomy. None of our study patients underwent laminoplasty. Several recently published studies have demonstrated that laminoplasty ${ }^{(1,5,13)}$ and hemilaminectomy ${ }^{(14)}$ have superiority over total laminectomy concerning the prognosis and outcomes. However, this finding was not concordant with our study findings because among 45 patients who underwent total laminectomy, only one received a fixation operation after the second operation. This mismatch could have been related to the preservation of bilateral facet joints or the relatively small sample size of our patients.

Even though GTR of meningioma, schwannoma, lipoma and epidermoid cysts has been considered feasible(6), a literature review regarding the resection of IDEM lesions revealed that most IDEM lesions were resected subtotally ${ }^{(6,15,16)}$. Notably, there are several obstacles in performing GTR of all IDEM lesions, such as adhesions to the spinal cord because of haemorrhage, inflammation or subpial localisation ${ }^{(1,6,17)}$. In addition, another obstacle is the attachment of critical structures to extradural components outside the spinal canal, such as the vertebral artery in cervical tumours and the abdominal aorta in lumbar tumours. Moreover, giant-size tumours, as well as invasion of the bone and facet joints could be other surgical impediments ${ }^{(6)}$. Notably, patients with an IDL (IDEM/IDIM) require longterm observation after surgical resection to avoid serious complications of recurrence ${ }^{(1,6,6)}$. However, assessment of MRI, excellent knowledge of the anatomy of surrounding structures and selection of appropriate surgical techniques and approaches could overcome these obstacles. In the past three decades, the high rate of GTR in patients with intradural tumours can be explained based on the use of IONM during surgical interventions. The IONM guides surgeons to perform surgeries more safely and aggressively ${ }^{(1,6,7,15)}$.

Postlaminectomy kyphosis is highly correlated with bilateral facetectomybecause of the increase in the degree of angulations with time ${ }^{(5,6)}$. Postlaminectomy kyphosis is typically associated with a total laminectomy of more than two levels. One of our schwannoma cases was treated with posterior instrumentation and no facets were removed, and the patient developed gradual stability. Although laminectomy is recommended to be less than $12 \mathrm{~mm}$, bilateral facetectomy at one or more levels can cause acute angular kyphosis(5). Despite the high control of tumour recurrence, unilateral facetectomy may predispose to a spinal deformity, such as angular kyphosis or scoliosis with angular kyphosis, which may both cause spinal cord compression ${ }^{(5,6)}$.

Upon literature review regarding the approaches for the resection of IDL, several studies have recommended and preferred laminoplasty and hemilaminectomy rather than total laminectomy ${ }^{(1,6,7,15)}$. However, insufficient statistical evidence or first level (prospective) studies preclude affirming the efficacy of laminoplasty or hemilaminectomy. Through two different studies, Abdallah et al. ${ }^{(1,15)}$ reported excellent long-term surgical outcomes of laminoplasty for ependymoma in a few children and untethering tethered cord syndrome. Another study by Kim et al. ${ }^{(13)}$ revealed that laminoplasty prevented postoperative spinal deformities after the removal of spinal cord tumours in 16 cases compared with 89 cases of laminectomy. In addition, studies of Emel et al.(6) and Abdallah et al. ${ }^{(1,15)}$ have evidenced the superiority of laminoplasty.

In adults, removal of the facet joints unilaterally for tumours located in the cervical or thoracic spine does not require fusion but might be necessary for those located in the lumbar spine ${ }^{(5,6,13,17,18)}$. Several approaches have been described for resection of IDEM and IDIM lesions, such as mini-open (minimal invasive) and traditional open laminectomy or laminoplasty; however, a wide laminectomy is still the standard approach used to explore extra- and intradural compartments. 
Indications for radiotherapy in cases with intradural lesions include high-grade glial tumours, seeding metastasis, subtotal resection in WHO grade II lesions or highly radiosensitive neoplasms, such as metastasis of germ cell tumours and lymphoma. Posterior instrumentation is advocated in patients with significant kyphosis or with lesions at the thoracolumbar junction, as well as in patients who undergo two or more adjacent laminectomies to supplement the anterior reconstruction ${ }^{(5,5,9,19)}$.

\section{Study Limitations}

Nonetheless, our study had few limitations. Our study sample included all the documented spinal lesion cases that were determined using MRI and histopathologically proven at our hospital over 6-year period. Therefore, the sample size was relatively small $(n=53)$. Moreover, the sample does not represent a wide geographical area because all patients were from our city and surrounding area. Hence, the results represent a single institute experience and could not be generalised for other institutes. In addition, the study design was retrospective. Therefore, further prospective studies with large sample size and long follow-up periods are necessary to systematically investigate these findings.

\section{CONCLUSION}

Our treatment approaches were based on several factors, such as the patient's age, estimated survival, the nature of the lesion and the presenting symptoms. Regarding the surgical prognosis and necessity of postoperative posterior fixation, we did not find a statistical difference supporting the superiority of hemilaminectomy over total laminectomy. Nevertheless, further large, prospective studies are needed to confirm our results.

\section{Ethics}

Ethics Committee Approval: This retrospective study was approved by the medical ethics committee of Bakırköy Training and Research Hospital in December 2015, bearing decision number: 2015/508.

Informed Consent: Written informed consent was obtained from all patients for publication of their cases and accompanying images.

\section{Authorship Contributions}

Concept: M.A., A.A., Design: A.A., Ö.E.S., Data Collection or Processing: M.A., A.A., Analysis or Interpretation: A.A., M.G.P., Literature Search: A.A., M.G.P., Writing: A.A.

Conflict of Interest: No conflict of interest was declared by the authors.

Financial Disclosure: The authors declared that this study received no financial support.

Note: Drs. Asiltürk and Abdallah contributed equally to this work. Both of authors deserve the first name.

\section{REFERENCES}

1. Abdallah $A$, Emel $E$, Gündüz $H B$, Sofuoğlu ÖE, Asiltürk $M$, Abdallah BG. Long-term surgical resection outcomes of pediatric myxopapillary ependymoma: Experience of two centers and brief literature review. World Neurosurg. 2020;136:e245-61.

2. Chikani MC, Okwunodulu O, Mesi M, Mezue WC, Ohaegbulam SC, Ndubuisi CC. Surgically Treated Primary Spinal Cord Neoplasms in Southeastern Nigeria. J Neurosci Rural Pract. 2018;9:137-9.

3. Emel E, Abdallah A, Özer AF. Taking history and patient assessment in spinal surgery. In: Özer AF, Arslantaş A, Dalbayrak S (Eds.), Principles of Spine Surgery, Volume-1. Izmir: Intertıp Inc; 2017: 99-108.

4. Sellin JN, Tatsui CE, Rhines LD. Assessment and treatment of benign intradural extramedullary tumors. In: Winn HR, editor. Youmans \& Winn Neurological Surgery. 7th ed. Philadelphia: Elsevier; 2017: 2428-34.

5. Emel E, Abdallah A, Özer AF. Decompressive approaches to the lumbar spinal stenosis. In Özer AF, Arslantaş A, Dalbayrak S (Eds.), Principles of Spine Surgery, Volume-2. Izmir: Intertıp Inc; 2017:767-82.

6. Emel E, Abdallah A, Sofuoğlu EO, Ofluoğlu $A E$, Güneş $M$, Güler $B$, et al. Long-term Surgical Treatment Outcomes of Spinal Schwannomas: Retrospective analysis of 49 consecutively operated cases. Turk Neurosurg. 2017;27:227-36.

7. Sofoğlu ÖE, Abdallah A. Pediatric spinal ependymomas. Med Sci Monit. 2018;24:7072-89.

8. Abdallah A, Asiltürk M, Uysal ML, Emel E, Güler Abdallah B, Bilgiç $B$, Gündoğdu G. Primary Intracranial Germinomas: Retrospective Analysis of Five Consecutively Operated Cases. Turk Neurosurg. 2018;28:29-35.

9. Asiltürk $M$, Abdallah A, Sofuoğlu ÖE. Radiologic-Histopathologic Correlation of Adult Spinal Tumors: A Retrospective Study. Asian J Neurosurg. 2020. Accepted for publication on Jan 24, 2020 (e-pub).

10. Sakaura H, Hosono N, Mukai Y, Ishii T, Yonenobu K, Yoshikawa H. Outcome of total en bloc spondylectomy for solitary metastasis of the thoracolumbar spine. J Spinal Disord Tech. 2004;17:297-300.

11. Fourney DR, Abi-Said D, Lang FF, McCutcheon IE, Gokaslan ZL. The use of pedicle screw fixation in the management of malignant spinal disease: experience in 100 consecutive procedures. I Neurosurg. 2001;94(Suppl 1):S25-37.

12. Gokaslan ZL, York JE, Walsh GL, McCutcheon IE, Lang FF, Putnam JB Jr, Wildrick DM, Swisher SG, Abi-Said D, Sawaya R. Transthoracic vertebrectomy for metastatic spinal tumors. J Neurosurg. 1998;89:599-609.

13. Kim SH, Chin DK, Yoon YS, Jin BH, Cho YE, Kim YS. Spinal instability following for spinal cord tumors: Laminoplasty vs. laminectomy. J Korean Neurosurg Soc. 2001;30:S61-7.

14. Sarioglu AC, Hanci M, Bozkus H, Kaynar MY, Kafadar A. Unilateral hemilaminectomy for the removal of the spinal space-occupying lesions. Minim Invasive Neurosurg. 1997;40:74-7.

15. Abdallah A, Emel E, Abdallah BG, Asiltürk M, Sofuoğlu ÖE. Factors affecting the surgical outcomes of tethered cord syndrome in adults: a retrospective study. Neurosurg Rev. 2018;41:229-39.

16. Conti P, Pansini G, Mouchaty H, Capuano C, Conti R. Spinal neurinomas: Retrospective analysis and long-term outcome of 179 consecutively operated cases and review of the literature. Surg Neurol. 2004;61:34-43.

17. Klimo $\mathrm{P} \quad J$ r, Schmidt $\mathrm{MH}$. Surgical management of spinal metastases. Oncologist. 2004;9:188-96.

18. Jeon JH, Hwang HS, Jeong JH, Park SH, Moon JG, Kim CH. Spinal schwannoma; analysis of 40 Cases. J Korean Neurosurg Soc. 2008;43:135-8.

19. Witham TF, Khavkin YA, Gallia GL, Wolinsky JP, Gokaslan ZL. Surgery insight: current management of epidural spinal cord compression from metastatic spine disease. Nature Clinical Practice Neurology. 2006;2:87-94. 